\title{
Coefficient of Discharge and Energy Loss Attained Over a Sharp Crested Rectangular Weir
}

\author{
D. Jawaharlal*, M. Srinivasulu, G. Manoj Kumar and G. Swetha \\ Department of Soil and Water Engineering, College of Agricultural Engineering, India \\ *Corresponding author
}

\section{A B S T R A C T}

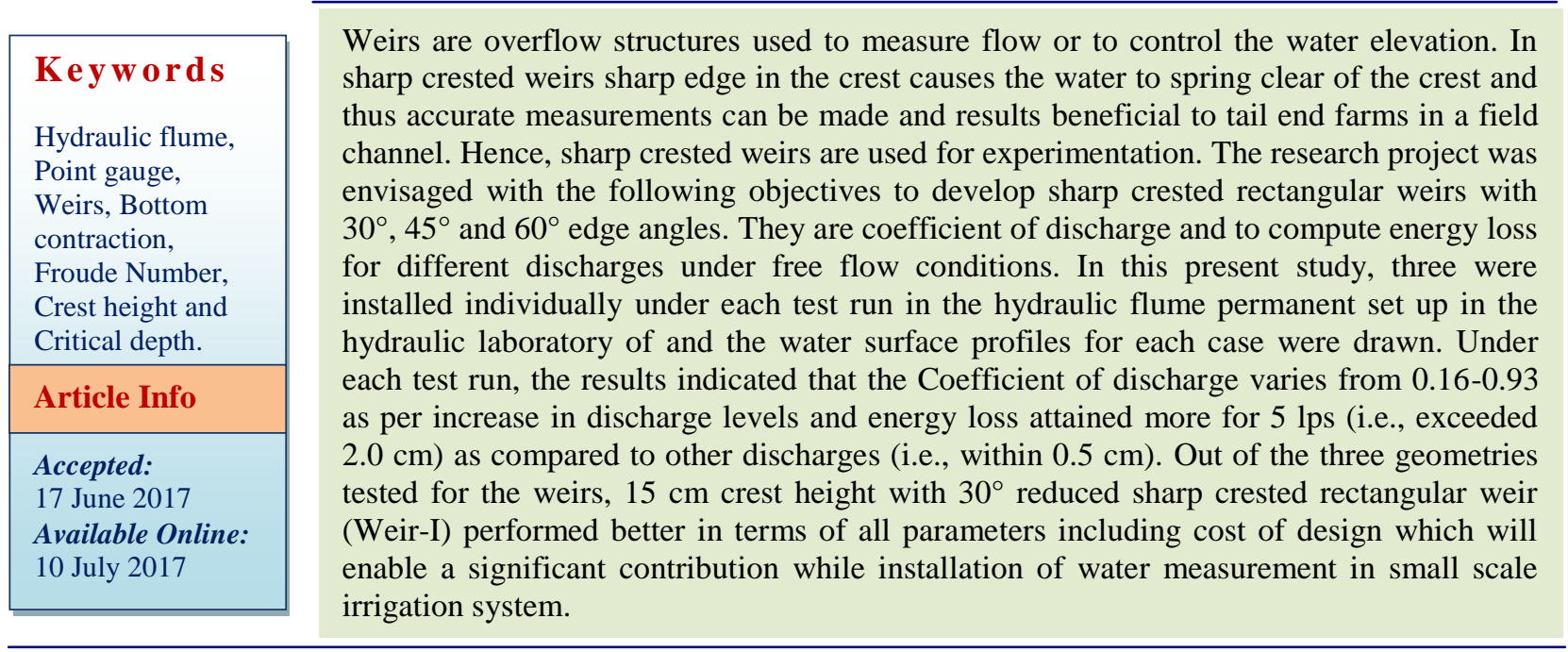

\section{Introduction}

Sharp crested weirs are devices useful for flow measurement in water courses and field channels where the flow is of the order of 10 cubic feet per second ( 0.3 cumecs) and where head loss considerations are secondary. The initial cost of a weir is very low in comparison to sophisticated electronic devices. Its accuracy depends upon how such weirs are maintained and how accurately the head measurements are done. In sharp crested weirs sharp edge in the crest causes the water to spring clear of the crest and thus accurate measurements can be made and results beneficial to tail end farms in a field channel. Hence, sharp crested weirs are used for experimentation to study the flow characteristics for free flow conditions at low discharges.

On exploring the literature, Konstantinos X. Soulis (2012) conducted a simple and lowcost flow measurement method for the field calibration of weirs and concluded that the partial volumetric method can provide a simple, low-cost, but accurate flowmeasurement. Raouf E. Baddour (2008) explained about sharp crested Polynomial weirs can be applied in agricultural and municipal engineering to produce a wide range of head-discharge behaviour, including 
the proportional linear characteristics of the Sutro weir.

There are several forms of the weir headdischarge equation, but for all weirs it has the general form

$\mathrm{Q}=\mathrm{C}_{\mathrm{v} .} \mathrm{C}_{\mathrm{d} \cdot f(h)}$

$\mathrm{Q}=$ Discharge (lps)

$\mathrm{C}_{\mathrm{v}}=$ Coefficient of velocity (to allow for approach velocity); and

$\mathrm{C}_{\mathrm{d}}=$ Coefficient of discharge (to allow for contraction and frictional resistance)

Several methods are available for calibrating weirs. Among them, the methods most frequently used are

Against measured flows (e.g., volumetric, area-velocity, tracer dilution, electromagnetic slope area method),

Against another calibrated flow-measurement structure,

Pre-calibration of the measuring structure in the laboratory and Model studies.

Weirs can be used in applications in which highly accurate discharge measurements are required. In this case, the field-calibration method to be used must have comparable or better accuracy than the weir. The volumetric flow-measurement is a very accurate and simple method, but it usually cannot be applied in the field, except for very small flows. Other field flow-measurement methods are generally more complicated or not accurate enough for the calibration of weirs. The pre-calibration of the measuring structure in the laboratory or the model studies can provide complete and accurate calibration. By keeping the above practical requirements in view, this research project is envisaged to fulfil the objectives to develop of sharp crested rectangular weirs with $30^{\circ}, 45^{\circ}$ and $60^{\circ}$ edge angles the relationship between all the parameters above are compared with considered discharges (i.e., 5, 10, 15 and 20 lps).

\section{Materials and Methods}

The experiments were conducted in hydraulic flume of $10 \mathrm{~m}$ long and $0.3 \mathrm{~m}$ wide with motorized bed slope alteration facility at College of Agricultural Engineering, Bapatla. Three sharp crested critical flow weirs were fabricated and tested under four different discharges. The water surface profiles along the centre line of the flume were drawn.

Initially for $20 \mathrm{lps}$ discharge, the water surface levels with distance were recorded at $5 \mathrm{~cm}$ intervals along the centre line of hydraulic flume by moving the point gauge on the rails at $18.5 \mathrm{~cm}$ height. The starting of the water surface profile measurement is from $106 \mathrm{~cm}$ before and $169 \mathrm{~cm}$ after the sharp edge of the weir.

The process of recording the water surface profiles has been repeated with remaining three discharges of $15 \mathrm{lps}, 10 \mathrm{lps}$ and 5lps. The sharp crested weir-I has been replaced by weir-II once and followed by weir-III by taking all precautions as in the installation of weir-I.

\section{Results and Discussion}

Different locations of the critical depth occurred, coefficient of discharges, Froude numbers and energy losses for different weirs for different discharges under free flow are discussed in this study

\section{Coefficient of discharge $\left(C_{d}\right)$ values for different discharges for different Weirs}

The coefficient of discharge for different weirs were calculated with the experimental 
data as per the standard methodology explained in previous chapter and were presented in table 1 and were represented in figure 1 .

The co-efficient of discharge increased with increasing of discharge for all the weirs. For 5 lps, $C_{d}$ values varied like $0.16,0.17,0.16$ and for $10 \mathrm{lps}$ it remained as constant value that is
0.37 and for $15 \mathrm{lps}$ it varied like $0.63,0.59$, 0.63 and for $20 \mathrm{lps}$ it increased like 0.92 , $0.93,0.93$ for weir-I, weir-II, weir-III respectively. For each weir as the discharge increases $C_{d}$ values also increased. It can be concluded that $\mathrm{C}_{\mathrm{d}}$ value increases with increase in discharge due to higher velocity and less friction. Hence weirs can be operated at higher discharges at field channels.

Table.1 $\mathrm{C}_{\mathrm{d}}$ values for different discharges for different weirs

\begin{tabular}{|c|c|c|c|c|}
\hline \multirow{2}{*}{ S.No } & \multirow{2}{*}{$\begin{array}{c}\text { Discharge } \\
(\mathbf{L} / \mathbf{s})\end{array}$} & \multicolumn{3}{|c|}{ Coefficient of Discharge $\left(\mathbf{C}_{\mathbf{d}}\right)$} \\
\cline { 3 - 5 } & 5 & Weir-I & Weir-II & Weir-III \\
\hline 1 & 10 & 0.16 & 0.17 & 0.16 \\
\hline 2 & 15 & 0.37 & 0.37 & 0.37 \\
\hline 3 & 20 & 0.92 & 0.59 & 0.63 \\
\hline 4 & & 0.93 & 0.93 \\
\hline
\end{tabular}

Table.2 Energy loss for different discharges of different weirs

\begin{tabular}{|c|c|c|c|c|}
\hline \multirow{2}{*}{ S.No } & \multirow{2}{*}{$\begin{array}{c}\text { Discharge } \\
\text { (lps) }\end{array}$} & \multicolumn{3}{|c|}{$\operatorname{Energy} \operatorname{Loss}(\Delta \mathbf{E})(\mathrm{cm})$} \\
\hline & & Weir-I & Weir-II & Weir-III \\
\hline 1 & 5 & 4.75 & 2.73 & 2.03 \\
\hline 2 & 10 & 0.578 & 0.04224 & 0.03633 \\
\hline 3 & 15 & 0.0831 & 0.0179 & 0.0137 \\
\hline 4 & 20 & 0.0582 & 0.0072 & 0.0059 \\
\hline
\end{tabular}

Fig.1 Relationship between discharge and coefficient of discharge under free flow conditions

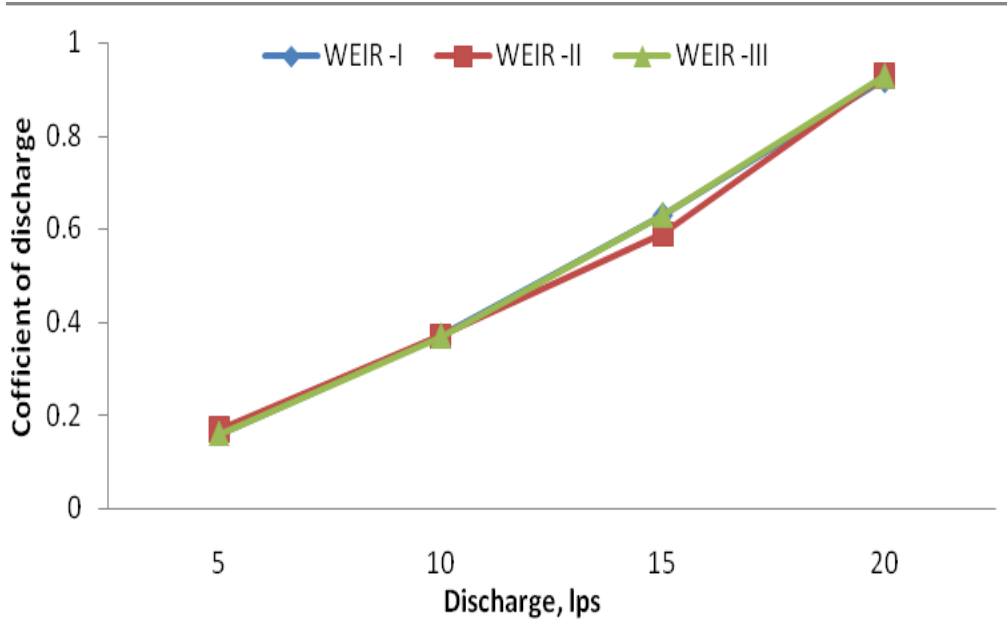


Fig.2 Relationship between discharge and energy loss under free flow conditions

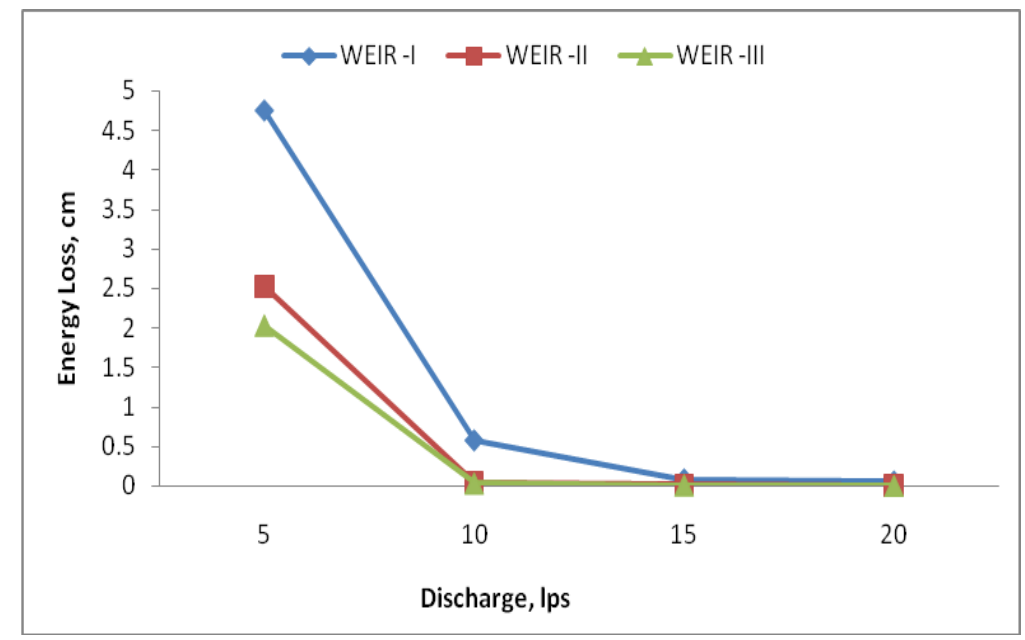

Plate.1 Weirs used for experimentation

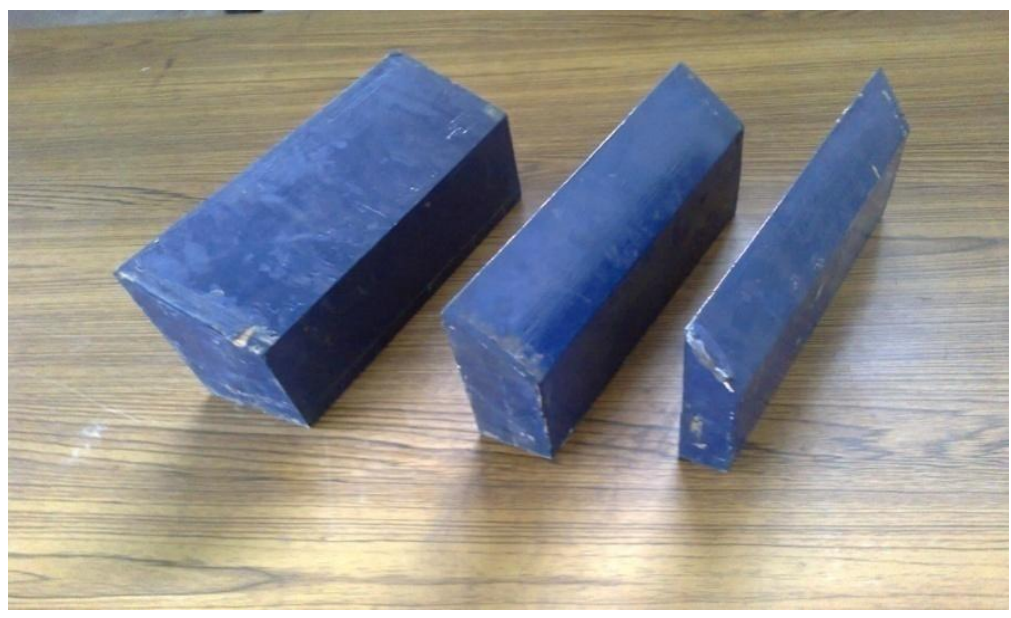

The energy loss for different discharges of different weirs were calculated as discussed in the previous chapter and is presented in table 2 .

For all the weirs energy loss is very high at 5 lps and remains constant for remaining discharges. As we know that more energy loss is beneficiary, hence from the above values weir-I can be taken as more efficient among the three weirs used.

It is concluded that the location of critical depth for all weirs at different discharges is away from the weir, Coefficient of discharge varies from $0.16-0.93$ as per increase in discharge levels and Energy loss attained is more for $5 \mathrm{lps}$ (i.e., exceeded $2.0 \mathrm{~cm}$ ) as compared to other discharges (i.e., within 0.5 $\mathrm{cm}$ ) out of four discharges $5 \mathrm{lps}$ is optable discharge, which reduces velocity and increases head of the flow. It is concluded that out of the three geometries tested for the weirs, $15 \mathrm{~cm}$ crest height with $30^{\circ}$ reduced sharp crested rectangular weir (i.e., Weir-I) performed better in terms of all parameters except cost of design. 


\section{References}

Ghanshyam Das, 2010. Hydrology and Soil Conservation Engineering, PHI Learning Pvt. Ltd., New Delhi,

Konstantinos X. Soulis, 2012.Field Calibration of Weirs Using Partial Volumetric Flow Measurements. Journal of Irrigation and Drainage Engineering, ASCE. 138:481-484.

Reg Herschy, 1995.General purpose flow measurement equations for flumes and thin plate weirs. Flow Measurement
Instrumentation, 6(4), 283-293.

Raouf E. Baddour, 2008. Head-discharge equation for sharp-crested polynomial weir. Journal of Irrigation and Drainage Engineering, ASCE. 134(2): 260-262.

Ramamurthy A.S., Junying Qu, Chao Zhai and DiepVo, 2007. Multislit Weir Characteristics. Journal of Irrigation and Drainage Engineering, ASCE. 133(2): 198-200.

\section{How to cite this article:}

Jawaharlal, D., M. Srinivasulu, G. Manoj Kumar and Swetha, G. 2017. Coefficient of Discharge and Energy Loss Attained Over a Sharp Crested Rectangular Weir. Int.J.Curr.Microbiol.App.Sci. 6(7): 1051-1055. doi: https://doi.org/10.20546/ijcmas.2017.607.126 